\title{
O IMPACTO DA LIDERANÇA PARTILHADA NO DESEMPENHO ORGANIZACIONAL PERCECIONADO
}

\begin{abstract}
Resumo: Atualmente, a complexidade do ambiente de negócios torna difícil que apenas um gestor possa desempenhar os vários papéis que lhe são exigidos, pelo que, surge a conceção de liderança partilhada. Este estudo visa estudar um modelo específico em que a relação entre a liderança - competências de gestão e liderança partilhada - e o desempenho organizacional percebido, é mediada através da cultura e da confiança. Foi utilizado o método quasiexperimental em amostra restrita, tendo sido recolhidos os dados relativos às variáveis em estudo numa mesma empresa em dois momentos distintos. As hipóteses formuladas, com o intuito de testarem o modelo, foram validadas pelos resultados obtidos.
\end{abstract}

Albino Lopes ${ }^{1}$

Pedro Baioa ${ }^{2}$

Palavras-chave: liderança partilhada; papéis de liderança; competências; desempenho organizacional percebido.

\begin{abstract}
Currently, the business environment complexity makes difficult that only one manager could perform the several which roles demanding to him. Due to this a shared leadership is emerging. The present research has the objective to develop a specific model in which is established a relationship between leadership - management competencies and shared leadership - and the perceived organizational performance, measured through the culture and the trust. A quasi-experimental method was applied in a restricted sample in which the participants come from the same company. The data was collected in two different moments. The hypotheses were formulated in order to test the proposed model. The results suggest the model validation.
\end{abstract}

KeyWords: shared leadership; leadership roles; competencies; perceived organizational performance.

\footnotetext{
${ }^{1}$ Professor Catedrático do ISCSP/UTL. E-mail: alopes@ iscsp.utl.pt

${ }^{2}$ Mestre em gestão pelo ISCTE. O texto retoma no essencial a sua tese de mestrado, realizada sob a supervisão do primeiro, no âmbito de uma intervenção organizacional realizada na empresa em estudo.
} 


\section{Albino Lopes e Pedro Baioa}

\section{CONTEXTO E FORMULAÇÃO DO PROBLEMA}

As mudanças constantes no ambiente de negócios - globalização da economia e dos mercados de trabalho e de capital globais, e das tecnologias de informação - exigem das organizações níveis de desempenho, cada vez mais elevados (Lawler III, 1999). Consequentemente, torna-se fundamental que as organizações alcancem vantagem competitiva para que, desta forma, sobrevivam e prosperem.

De acordo com a Abordagem Baseada nos Recursos (Resource-Based View), o único meio de obtenção de vantagem competitiva é através da criação de valor com recursos e/ou capacidades raros ou difíceis de imitar (Barney, 1991, 1995; Grant, 1991, 2002), sendo também importante o papel do contexto (Barney et al., 2001). Dado que as fontes tradicionais de vantagens competitivas têm-se tornado cada vez mais fáceis de imitar (Becker e Gehart, 1996), De Saá-Pérez e Garcia-Falcón (2002) referem que seriam os recursos humanos de uma organização, através das suas competências, que têm o potencial de criar valor na mesma. Consequentemente, torna-se fundamental que os mesmos desenvolvam as suas competências.

Por outro lado, muitas foram as variáveis consideradas como causadoras de um bom ou mau desempenho organizacional, por exemplo: Davis et al. (2000) dá ênfase à confiança; Kotter e Heskett (1992) salientam a cultura organizacional; Cameron et al. (2006) dão ênfase à liderança; entre outros. Embora todas as variáveis enunciadas tenham o seu impacto no desempenho organizacional, surgem evidências que a cultura e a confiança assumem um papel de mediação entre a liderança (variável independente) e o desempenho (variável dependente), e não propriamente um papel de causalidade.

Torna-se, também, relevante referir duas questões fundamentais. Em primeiro lugar, é necessário mencionar que alguns autores (e.g., Hart e Quinn, 1993) equivalem o desempenho e a eficácia da organização à perceção dos sujeitos, i.e., estas variáveis podem ser avaliadas pelas perceções dos sujeitos. A outra questão está relacionada com o surgimento de uma nova conceção da liderança - a liderança partilhada, segundo a qual a liderança pode ser repartida por um conjunto de líderes (Bligh et al., 2006).

O presente texto visa, desta feita, testar este modelo, em que a liderança é entendida como variável causadora (englobando as questões da liderança partilhada e a das competências dos líderes), o desempenho organizacional como variável dependente, e a cultura e a confiança como variáveis mediadoras. $\mathrm{O}$ estudo desta problemática poderá contribuir para uma melhor compreensão deste fenómeno, o que, consequentemente, 
permitirá mais facilmente prever e otimizar o desempenho das organizações, para que, desta forma, estas sobrevivam e prosperem num ambiente de negócios complexo e dinâmico.

\section{LIDERANÇA E COMPETÊNCIAS}

\subsection{Liderança e liderança partilhada}

Inúmeras teorias sobre a liderança foram aparecendo ao longo dos anos, e segundo Yukl (2009), existem cinco grandes teorias de liderança: traços, comportamento, poder-influência, situacional e integrativa. Contudo, estas teorias assentavam na asserção de que existia um único indivíduo a exercer uma posição de liderança. Surgiram, entretanto, evidências de que a liderança pode ser partilhada (Pearce, 2004). Liderança partilhada, segundo Pearce e Conger (2003), pode ser definida como um processo de influência dinâmico e interativo, levado a cabo por um conjunto de indivíduos, e em que o objetivo será o alcance dos resultados esperados (Bligh et al., 2006).

As probabilidades de sucesso deste modo de liderança sobem quando os líderes desempenham papéis diferentes e complementares, sabem trabalhar em conjunto, lidar com a divisão de crédito, comunicar com eficácia, lidar com crises, alocar e voltar a alocar tarefas conjuntas e decisões, bem como desenvolver posições comuns em assuntos chave (O'Toole et al., 2002).

Em conformidade com o que foi referido, Pitcher (1993) refere que devem existir três papéis/perfis de líder (Quadro 1) numa equipa de gestão/liderança: artista (desafia a gestão), artesão (coloca questões sobre estabilidade, continuidade e lealdade) e tecnocrata (fiscaliza as funções de controlo). Segundo Lopes e Moreira (2004), esta abordagem de Patrícia Pitcher enquadra-se com a realidade das organizações de sucesso. Os autores, no entanto, sugerem a possibilidade de existência de um quarto papel/perfil (designado por "político"), sendo este necessário para obter a cooperação entre os restantes papéis/perfis.

Quadro 1 - Papéis/perfis do líder numa organização

\begin{tabular}{l|l|l} 
Papel & Características & Visão Estratégica \\
\hline \multirow{3}{*}{ Artista } & $\begin{array}{l}\text { Imprevisível, divertido, } \\
\text { estável, audaz, intuitivo, }\end{array}$ & $\begin{array}{l}\text { A visão estratégica de um artista } \\
\text { raramente é detalhada ou }\end{array}$ \\
& $\begin{array}{l}\text { empolgante, emocional, } \\
\text { visionário, }\end{array}$ & especifica. Estes "líderes \\
empreendedor, & visionários inspiram com \\
& metáforas e não com descrições \\
& inspirador. & detalhadas do futuro".
\end{tabular}




\begin{tabular}{|l|l|l|}
\hline Artesão & $\begin{array}{l}\text { Equilibrado, prestável, } \\
\text { honesto, sensível, } \\
\text { responsável, digno de } \\
\text { confiança, realista, firme, } \\
\text { razoável, previsível. }\end{array}$ & $\begin{array}{l}\text { A visão estratégica de um artesão é } \\
\text { realista e, consequentemente, de } \\
\text { alcance médio tanto para o passado } \\
\text { como para o futuro. }\end{array}$ \\
\hline Tecnocrata & $\begin{array}{l}\text { Cerebral, difícil, } \\
\text { inflexível, duro, intenso, } \\
\text { orientado para os } \\
\text { detalhes, determinado, } \\
\text { fastidioso, obstinado, } \\
\text { racional. }\end{array}$ & $\begin{array}{l}\text { A sua visão estratégica, se assim se } \\
\text { puder chamar, consiste em analisar } \\
\text { com um grande detalhe a visão que } \\
\text { outro criou. Incapazes de criar, os } \\
\text { tecnocratas passam muitas vezes } \\
\text { como sendo pessoas brilhantes, } \\
\text { devido às suas virtudes analíticas e } \\
\text { técnicas. }\end{array}$ \\
\hline
\end{tabular}

Fonte: Adaptado de Pitcher (1997) por Lopes e Moreira (2004, p. 92).

\subsection{Conceito de competências}

O desenvolvimento inicial do conceito de competências deveu-se ao contributo de autores como McClelland (1973), Boyatzis (1982), Kolb (1984), Morgan (1988), Nordhaug (1993) (Sandberg, 2000) e Spencer e Spencer (1993) (Felício et al., 2007). Os conceitos desta corrente, que salientam os atributos dos indivíduos necessários para atingir um bom desempenho, pertencem às abordagens racionalistas da competência, podendo estas estar orientadas para o trabalhador, para a função, ou para ambas (Sandberg, 2000). Este tipo de abordagens, ao considerar a independência dos atributos em relação ao contexto, tem sido bastante criticado, pelo que surge como alternativa a abordagem interpretativa, que já considera essa dependência (Sandberg, 2000).

Boterf (1998, p. 150) considera que «as competências podem ser encaradas como uma resultante de três factores: conhecimento de como agir, que supõe o saber combinar e mobilizar recursos pertinentes (...); o querer agir, que se refere à motivação e envolvimento do indivíduo; a capacidade de agir, que remete para a existência de um contexto, de uma organização do trabalho e de condições sociais que tornam possíveis e legitimas o adoptar de responsabilidades, pelos indivíduos». Este conceito apresenta características mais construtivas, dado que não engloba apenas os atributos e o contexto, mas também tem atenção à envolvente social do indivíduo e à predisposição do indivíduo para agir e para se envolver num determinado contexto.

Schwartz (1997), por seu lado, refere que "a competência no trabalho é uma combinatória problemática de ingredientes heterogéneos" (p. 15). Trata-se de uma abordagem inovadora do autor (1997), segundo a qual a 
competência é, assim, composta por seis ingredientes: 1) dimensão conceptual das situações de trabalho; 2) historicidade das situações de trabalho; 3) procura estabelecer consonância entre os dois primeiros ingredientes; 4) quadro relacional e os valores das pessoas; 5) recorrência parcial do quarto ingrediente sob os restantes; 6) visa gerir e criar sinergias entre individualidades e coletivos de trabalho.

No âmbito das competências de liderança, Felício et al. (2007) destacam os contributos de Mintzberg (1989), Yukl (1989) e Quinn e Rohrbaugh (1983), sendo este último baseado na proposta de um modelo de competências de gestão - Modelo dos Valores Contrastantes (Competing Values Framework - CVF).

\subsection{Competências de liderança - Modelo dos Valores Contrastantes}

O Modelo dos Valores Contrastantes foi desenvolvido por Quinn e Rohrbaugh (1983) aquando do estudo da eficácia organizacional e, de acordo com Have et al. (2003), o modelo é considerado um dos 40 modelos mais importantes na história da gestão (Felício et al., 2007). O modelo é composto por duas grandes dimensões - foco interno vs. foco externo e flexibilidade vs. controlo (Cameron e Quinn, 2005) que, ao serem sobrepostas, dão origem a quatro orientações (Figura 1). Por sua vez, a cada uma das orientações correspondem dois papéis - num total de oito papéis (Figura 1) - e a cada papel correspondem três competências num total de 24 competências (Quadro 2). Segundo Quinn et al. (1990), apud Felício et al. (2007, p. 21), competência significaria, assim, "colocar os conhecimentos e as capacidades no desempenho de determinada tarefa ou papel”.

Figura 1 - Modelo dos Valores Contrastantes

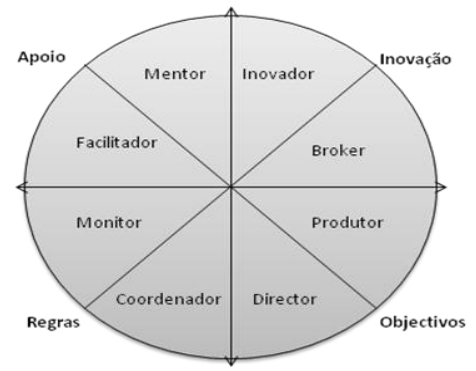

Fonte: Adaptado de Felício et al. (2007). 


\section{Albino Lopes e Pedro Baioa}

\section{Quadro 2 - Modelo dos Valores Contrastantes: competências, papéis}

e orientações

\begin{tabular}{|c|c|c|}
\hline Competências & Papéis & Orientações \\
\hline 1. Conviver com a mudança & \multirow{3}{*}{ Inovador } & \multirow{6}{*}{ Inovação } \\
\hline 2. Pensamento criativo & & \\
\hline 3. A Gestão da mudança & & \\
\hline 4. Criar e manter uma base de poder & \multirow{3}{*}{ Broker } & \\
\hline 5. Negociar acordos e compromissos & & \\
\hline 6. Apresentar ideias & & \\
\hline 7. Produtividade e motivação pessoal & \multirow{3}{*}{ Produtor } & \multirow{6}{*}{ Objectivos } \\
\hline 8. Motivar os outros & & \\
\hline 9. Gestão do tempo e do stresse & & \\
\hline 10. Tomada de iniciativas & \multirow{3}{*}{ Director } & \\
\hline 11.Fixação de metas & & \\
\hline 12. Delegação eficaz & & \\
\hline 13. Planificação & \multirow{3}{*}{ Coordenador } & \multirow{6}{*}{ Regras } \\
\hline 14. Organização e desenho & & \\
\hline 15. Controlo & & \\
\hline 16. Reduzir a sobrecarga de informação & \multirow{3}{*}{ Monitor } & \\
\hline 17. Analisar a informação criticamente & & \\
\hline 18. Apresentar a informação & & \\
\hline 19. Criação de equipas & \multirow{3}{*}{ Facilitador } & \multirow{6}{*}{ Apoio } \\
\hline 20. Tomada de decisões participativa & & \\
\hline 21. Gestão do conflito & & \\
\hline 22. Auto compreensão e compreensão dos outros & \multirow{3}{*}{ Mentor } & \\
\hline 23. Comunicação interpessoal & & \\
\hline 24. Desenvolvimento dos subordinados & & \\
\hline
\end{tabular}

Inúmeros autores salientam a relevância do modelo. Cameron et al. (2006) referem que o modelo permite albergar diferentes níveis de análise no que se refere à criação de valor, em que a necessidade de consonância entre os resultados da criação de valor e as dinâmicas individual e organizacional são fundamentais (Felício et al., 2007). Por outro lado, Sendelbach (1993) enumera muitas outras vantagens do modelo, tais como: facilita a compreensão da natureza de mudança da liderança de gestão e dilemas de gestão; utilização como ferramenta para educação, treino e desenvolvimento de líderes de gestão. 


\section{CULTURA}

Kotter e Heskett (1992) salientam a importância de uma cultura "forte" para a obtenção de bons desempenhos no ambiente de negócios atual, pelo que se torna relevante efetuar algumas considerações relativamente ao conceito e às dimensões da cultura.

Ao aprofundar o conceito de cultura, Cameron e Quinn (2005) referem que o interesse pelo mesmo observou-se a partir de 1980. Segundo os autores referidos, o conceito de cultura organizacional emerge de dois alicerces distintos: o alicerce antropológico (as organizações são culturas) e o sociológico (as organizações têm culturas); dividindo-se estes em duas abordagens díspares, a funcional (cultura emerge do comportamento coletivo) e a semiótica (cultura reside nas interpretações e cognições individuais).

Cameron e Quinn (2005) aludem que a cultura é um atributo da própria organização e que é espelhada pelo que é valorizado na mesma. Schein $(1992,1996)$ define cultura como um conjunto de assunções tácitas básicas partilhadas por um grupo de pessoas de como o mundo é e deve ser, e que determina as suas perceções, pensamentos, sentimentos e o seu comportamento. Hofstede (2001, p. 9) define cultura como "a programação colectiva da mente que distingue os membros de um grupo, ou categoria de pessoas, de outro". Ao observar os conceitos propostos por estes autores de referência no estudo da cultura organizacional, denota-se que os fundamentos básicos dos conceitos são os mesmos.

Por outro lado, e no que se refere às dimensões da cultura, muitas foram propostas nas últimas décadas (Cameron e Quinn, 2005). Consideramos relevante fazer referência às dimensões propostas por Quinn e Rohrbaugh (1983) aquando do desenvolvimento do Modelo dos Valores Contrastantes, dimensões já referidas anteriormente (interno vs. externo e flexibilidade vs. controlo) e que dão origem a quatro tipos de culturas - relações humanas, inovação, processos internos e objetivos. Cameron e Quinn (2005) referem que o conceito de cultura, no qual o modelo assenta, pertence à abordagem funcional do alicerce sociológico.

\section{CONFIANÇA}

A importância da confiança tem sido reconhecida pela literatura recente, sendo que Kramer (2006), por exemplo, identifica três vantagens da confiança em contexto organizacional: conduz à redução dos custos de transação; potencia sociabilidade espontânea e cooperação entre os membros; facilita formas de deferência às autoridades organizacionais. 


\section{Albino Lopes e Pedro Baioa}

Relativamente ao conceito de confiança, têm surgido divergências e conflito de posições (Mayer e Davis, 1999; Kramer, 2006). Hardy et al. (1998) referem que a confiança é muitas vezes encarada como previsibilidade ou como benevolência, mas que, no entanto, nenhuma destas perspetivas representa a complexidade da confiança. Assim, Mayer et al. (1995) apresentam um conceito mais abrangente, em que encaram a confiança como a predisposição de um indivíduo para ser vulnerável às ações de outro indivíduo.

Lane (1998) refere que a maior parte dos conceitos partilha normalmente três elementos, os indivíduos não terem de confiar à parte das relações sociais (em referência a Lewis e Weigert, 1985), meio de lidar com a incerteza e risco nas relações de troca, e a crença de que a aceitação do risco por uma parte não será tida como vantajosa pela outra parte.

Moreira (2005), com base na revisão de literatura efetuada, refere que existem três perspetivas da confiança: calculativa; baseada no valor ou normas; baseada em conhecimentos comuns. Kramer (2006), por seu lado, identifica a escolha racional (i.e. calculativa) e relacional. Dada a complexidade da noção de confiança, estas perspetivas de ambos os autores são complementares e não mutuamente exclusivas.

De acordo com Hardin (1991), a forma de se sair deste impasse cultural seria através da conceptualização da confiança como uma relação de três partes, as "propriedades" do que confia, os atributos do depositário da confiança e o domínio ou contexto onde a confiança é conferida (Kramer, 2006).

Mayer et al. (1995) desenvolveram um modelo multidimensional da confiança que apresenta as ideias propostas por Hardin (1991), pois a confiança é constituída pelo seguinte conjunto de dimensões: a disponibilidade do sujeito para confiar, a fidedignidade do depositário da confiança, entre outras. A fidedignidade é afetada pela capacidade, benevolência e integridade do depositário da confiança, e de acordo com Mayer e Davis (1999), a forma como estes fatores são combinados em fidedignidade é idiossincrático, tanto entre indivíduos como entre situações, significando isto que o impacto de cada um dos fatores na fidedignidade (subsequentemente na confiança) depende da situação/contexto.

\section{DESEMPENHO ORGANIZACIONAL}

As constantes mudanças no ambiente de negócios atual exige das organizações cada vez melhores desempenhos (Lawler III, 1999), pelo 
que se torna relevante definir e diferenciar o desempenho de outros conceitos muito semelhantes.

De acordo com Lebas e Euske (2002), o desempenho é, muitas vezes, equiparado a eficiência e a eficácia. No entanto, de acordo com Robalo (1995), o significado dos termos não é o mesmo. A eficiência refere-se ao melhor modo de atingir determinado objetivo (i.e., eliminação de "resíduos" e redundância), ou seja, eficiência está relacionada na forma de fazer as coisas (Robalo, 1995; Cameron e Quinn, 2005). A eficácia, por seu lado, é criada pelo controlo após a criação da eficiência (Cameron e Quinn, 2005). O desempenho, de acordo com Lebas e Euske (2002), pode ser entendido como o potencial de criação de valor durante um período de tempo. Consequentemente, e de acordo com Stivers (1994), Bradley e Pribram (1996) e Roberts (1996), o desempenho organizacional está, assim, relacionado com a eficiência das operações internas, e com a eficácia global, ou adaptabilidade e capacidade de reação ao ambiente externo e interno (Simon, 1998).

Por outro lado, Venkatraman e Ramanujam (1986) propõem três dimensões fundamentais do desempenho de uma empresa: financeira, negócio (engloba a financeira e a operacional) e eficácia organizacional. Normalmente, as dimensões do desempenho são estimadas por medidas objetivas, como são as de mercado, contabilísticas, operacionais, etc. (Venkatraman e Ramanujam, 1986). No entanto, e na impossibilidade do seu uso, pode recorrer-se a medidas subjetivas, como por exemplo, as perceções dos elementos da organização (Dess e Robinson Jr., 1984; Rowe e Morrow Jr., 1999; Tehrani e Noubary, 2005; Mabey e Gooderham, 2005).

\section{HIPÓTESES}

O presente estudo é baseado num modelo em que a liderança é a variável independente, o desempenho organizacional percebido é a variável dependente e a cultura e a confiança são as variáveis intermédias (Figura 2). 


\section{Albino Lopes e Pedro Baioa}

Figura 2 - Diagrama do modelo

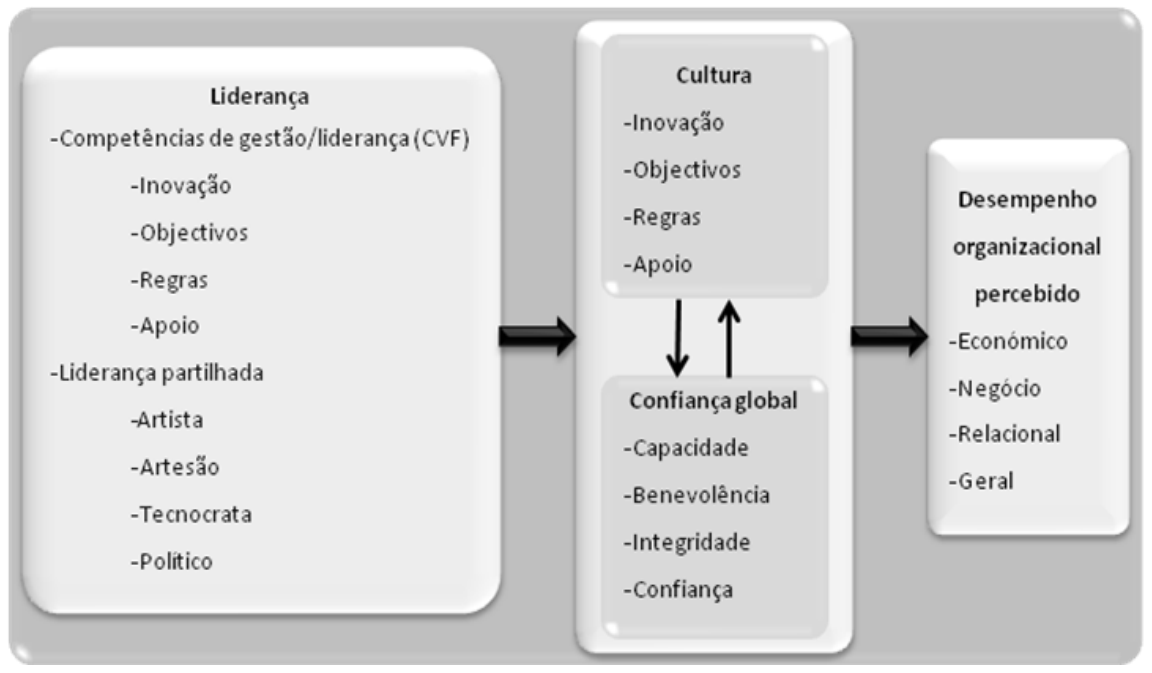

Em consonância com o modelo apresentado, teríamos um primeiro conjunto de hipóteses relacionadas o impacto das competências de um gestor sobre os hiatos culturais - diferença entre cultura desejada e percecionada - das áreas de gestão (i.e., apoio, inovação, regras e objetivos) e níveis de confiança. Assim:

$\mathbf{H}_{1 \mathbf{a}}$ : Um gestor que apresente maiores competências nos papéis de gestão/liderança de determinada área de gestão conseguirá obter um menor hiato cultural nessa mesma área da gestão.

$\mathbf{H}_{\mathbf{1 b}}$ : Um gestor que apresente maiores competências nos papéis de gestão/liderança conseguirá obter um maior nível de confiança por parte dos colaboradores.

O'Toole et al. (2002), como referido anteriormente, defendem que uma equipa de liderança deve ser composta por elementos que desempenhem papéis distintos e complementares. Desta forma, o conjunto seguinte de hipóteses procura avaliar o impacto de uma equipa de liderança com estas características nos hiatos culturais e no nível de confiança na gestão. Assim, temos:

$\mathbf{H}_{2 \mathbf{a}}$ : A existência de uma equipa de liderança em que os líderes desempenham papéis diferentes e complementares estará associada a um menor hiato cultural na organização. 
$\mathbf{H}_{2 b}$ : A existência de uma equipa de liderança em que os líderes desempenham papéis diferentes e complementares estará associada a um maior nível de confiança na gestão.

O terceiro conjunto de hipóteses está relacionado com o efeito nos hiatos culturais e níveis de confiança da existência de um quarto papel de liderança ("político"), sugerido por Lopes e Moreira (2004). Desta feita, temos:

$\mathbf{H}_{\mathbf{3}}$ : A existência de um elemento na equipa de liderança que desempenhe o papel de político, cuja função é a de atuar como facilitador institucional, estará associada a um menor hiato cultural na organização.

$\mathbf{H}_{3 \mathbf{b}}$ : A existência de um elemento na equipa de liderança que desempenhe o papel de político, cuja função é a de atuar como facilitador institucional, estará associada a um maior nível de confiança na gestão.

Foi referido anteriormente que Kramer (2006) salienta a importância da confiança para a obtenção de bons desempenhos; e que Kotter e Heskett (1992) salientavam a importância da cultura para os mesmos fins. Teremos, assim, um quarto conjunto de hipóteses que se encontram relacionadas com estas questões:

$\mathbf{H}_{4 \mathbf{a}}$ : Menores hiatos culturais na organização estarão associados a uma perceção mais elevada do desempenho organizacional.

$\mathbf{H}_{4 \mathrm{~b}}$ : Um maior nível de confiança dos colaboradores na gestão estará associado a uma perceção mais elevada do desempenho organizacional.

\section{METODOLOGIA}

Nesta investigação, o método utilizado foi o quasi-experimental em amostra restrita. $\mathrm{O}$ estudo foi realizado numa empresa de consultoria de tecnologias de informação, segundo uma perspetiva longitudinal (intervalo de cerca de 2 anos). Estabeleceu-se contacto com a empresa, no sentido de realizar o estudo na mesma. A base de inquérito foi constituída pelos vários colaboradores da empresa, e a população alvo pelos gestores de topo, o que significa que o estudo seguiu uma lógica de avaliação a $360^{\circ}$. Por outro lado, os dados relativos à organização interna da equipa de liderança foram recolhidos junto de um consultor organizacional da empresa. Por último, é necessário referir que os dados recolhidos foram analisados através de medidas descritivas.

\subsection{Instrumentos de recolha de dados}

Tendo em atenção as variáveis presentes no modelo em equação, foram utilizados quatro instrumentos de recolha de dados. 
Competências de gestão/liderança. Esta variável foi medida por um instrumento adaptado de Quinn et al. (1990) por Felício et al. (2007), que tem por base o modelo inicialmente conceptualizado por Quinn e Rohrbaugh (1983). Este instrumento é composto por um questionário de 48 itens, com uma escala de respostas de tipo Likert de cinco pontos, e que avalia um conjunto de 24 competências (Apêndice I).

Felício et al. (2007) testaram a validade do questionário através da Análise Factorial Confirmatória (AFC). De acordo com Browne e Cudeck (1993), valores de Root-Mean-Square Error of Approximation (RMSEA) até 0,05 indicam um ajustamento ótimo, 0,05 a 0,08 indicam um ajustamento razoável e a partir de 0,08 indicam que o ajustamento não é bom. Como se pode observar na Tabela 1, os valores obtidos de RMSEA encontram-se todos abaixo de 0,08 , o que significa que estamos na presença de ajustamentos razoáveis ou ótimos.

\begin{tabular}{|c|c|c|c|c|}
\hline \multirow{2}{*}{ Orientações } & \multirow{2}{*}{ Papéis } & \multicolumn{3}{|c|}{ RMSEA } \\
\hline & & Papéis & Orientações & Modelo global \\
\hline \multirow{2}{*}{ Inovação } & Inovador & 0,000 & \multirow{2}{*}{0,078} & \multirow{8}{*}{0,067} \\
\hline & Broker & 0,000 & & \\
\hline \multirow{2}{*}{ Objectivos } & Produtor & 0,022 & \multirow{2}{*}{0,074} & \\
\hline & Director & 0,000 & & \\
\hline \multirow{2}{*}{ Regras } & Coordenador & 0,076 & \multirow{2}{*}{0,069} & \\
\hline & Monitor & 0,000 & & \\
\hline \multirow{2}{*}{ Apoio } & Facilitador & 0,026 & \multirow{2}{*}{0,077} & \\
\hline & Mentor & 0,056 & & \\
\hline
\end{tabular}

Fonte: Baseado em Felício et al. (2007).

Relativamente à fidelidade, os autores (2007) aferiram que o instrumento apresentava uma boa fidelidade ao nível dos papéis, pois todos os Alfas de Cronbach (que medem a consistência interna) apresentam valores superiores a 0,7 (Tabela 2), que de acordo com Nunnally (1978), é o valor mínimo aceitável de consistência interna. Nunnally (1978) também refere que se podem considerar valores inferiores a 0,7 quando o número de itens é reduzido. 
Tabela 2 - Alfa de Cronbach: competências e papéis

\begin{tabular}{|l|c|}
\hline Papel & Alfa de Cronbach \\
\hline Inovador & 0,919 \\
\hline Broker & 0,879 \\
\hline Produtor & 0,876 \\
\hline Director & 0,845 \\
\hline Coordenador & 0,924 \\
\hline Monitor & 0,887 \\
\hline Facilitador & 0,943 \\
\hline Mentor & 0,925 \\
\hline
\end{tabular}

Fonte: Adaptado de Felício et al. (2007).

Cultura. O instrumento utilizado para diagnóstico da cultura organizacional é baseado no modelo conceptual desenvolvido por Robert E. Quinn e colaboradores, e que foi adaptado de Neves e Lopes (2000) por Felício (2007). Este instrumento é composto por um questionário de 16 itens (4 itens por dimensão), que permite avaliar os hiatos culturais de quatro tipo de culturas - inovação, objetivos, regras e apoio (Anexo).

No que se refere à validade do modelo da cultura percebida e da desejada, Felício (2007) obteve, através da AFC, um RMSEA de 0,066 e 0,040 , respetivamente; pelo que, o modelo da cultura percebida representa um ajustamento razoável e o modelo da cultura desejada representa um ajustamento ótimo.

A autora (2007) verificou, também, a fidelidade dos modelos da cultura percebida e da desejada. No modelo da cultura percebida, foram obtidos os seguintes Alfas de Cronbach por dimensão: inovação, 0,427; objetivos, 0,718; regras, 0,754; apoio, 0,816. Por sua vez, no modelo da cultura desejada foram obtidos: inovação, 0,315 ; objetivos, 0,638 ; regras, 0,739 ; apoio, 0,791. Pode-se observar que, à exceção da dimensão da inovação, todas as outras apresentam valores aceitáveis.

Confiança. O instrumento utilizado para medir esta variável é uma versão resumida do Modelo Integrativo da Confiança Organizacional, proposto por Mayer et al. (1995). Este instrumento é composto por um questionário de 21 itens, que avalia a fidedignidade do depositário da confiança e a confiança em termos gerais (Anexo). $\mathrm{O}$ instrumento tem uma escala de Likert de cinco pontos.

Mayer e Davis (1999) testaram a validade através da AFC, pela qual obtiveram um Comparative Fit Index - CFI - de 0,96 ( $2^{\mathrm{a}}$ onda) e $0,94\left(3^{\mathrm{a}}\right.$ onda). De acordo com Meyers et al. (2006), valores superiores a 0,90 indicam um bom ajustamento do modelo (Keating et al., 2008).

Relativamente à fidelidade, Mayer e Davis (1999) obtiveram Alfas de Cronbach superiores a 0,7 nas três vezes que o instrumento foi testado; a 
exceção é a dimensão da confiança ( $2^{\mathrm{a}}$ e $3^{\mathrm{a}}$ vezes, com 0,59 e 0,60 , respetivamente); no entanto, dado o número reduzido de itens, os valores são aceitáveis.

Desempenho organizacional. Para a medição desta variável, foi utilizado um instrumento adaptado de Delaney e Huselid (1996) por Felício (2007) o qual se apresenta em Anexo.

Felício (2007) validou o instrumento através da AFC, obtendo um RMSEA de 0,08, o que indica a presença de um ajustamento razoável. Quanto à fidelidade, a autora (2007), através do cálculo dos Alphas de Cronbach, obteve valores aceitáveis para a dimensão económica $(0,795)$, de negócio $(0,68)$, relacional $(0,788)$ e para o modelo global $(0,797)$.

\section{RESULTADOS}

No $1^{\circ}$ momento do estudo, o número de respondentes foi de 14 . No $2^{\circ}$ momento, o número de respondentes aumentou para 16.

Os resultados relativos às competências, confiança, cultura e desempenho organizacional serão apresentados no ponto seguinte.

\section{Cultura}

Ao observar a Figura 3, e no que se refere à cultura percepcionada no $1^{\mathrm{o}}$ momento, verifica-se que a dimensão do apoio era a que apresentava a média mais expressiva, sendo seguida pela inovação e objetivos; no polo oposto surge a dimensão regras. Do $1^{\circ}$ para o $2^{\circ}$ momento, a cultura percepcionada aumentou em todas as dimensões; todavia, no $2^{\circ}$ momento, a dimensão do apoio continua a ser a dimensão com a maior média e a dimensão das regras com a menor.

Figura 3 - Estudo 1: cultura percebida e desejada

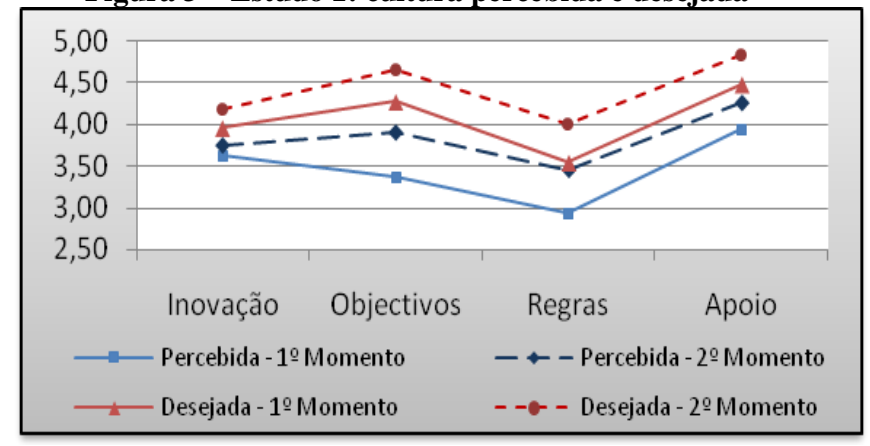


Examinando por outro prisma (Tabela 3), denota-se que, num $1^{\circ}$ momento, o maior hiato cultural - diferença entre cultura desejada e percepcionada - ocorre na dimensão dos objetivos e o menor ocorre na dimensão da inovação. No $2^{\circ}$ momento, o maior hiato cultural ocorre nos objetivos, sendo seguido pelo apoio e regras; em contrapartida surge a inovação (Tabela 3). Ao proceder à comparação dois momentos, denotase que os hiatos culturais diminuíram nas dimensões dos objetivos e das regras, e aumentaram nas dimensões da inovação e do apoio.

\begin{tabular}{|l|l|l|}
\multirow{2}{*}{ Tabela 3 - Estudo 1: hiatos culturais } \\
Dimensão & \multicolumn{2}{|c|}{ Hiato Cultural } \\
\cline { 2 - 3 } & $1^{\circ} \mathrm{M}$ & $2^{\circ} \mathrm{M}$ \\
\hline Inovação & 0,33 & 0,42 \\
\hline Objetivos & 0,90 & 0,75 \\
\hline Regras & 0,60 & 0,55 \\
\hline Apoio & 0,54 & 0,57 \\
\hline
\end{tabular}

\section{Desempenho organizacional}

No que se refere ao desempenho organizacional percepcionado, e como se denota pela Figura 4, a dimensão relacional é a que apresenta a maior média nos dois momentos, surgindo de seguida a dimensão geral. Contrariamente, surgem as dimensões: económica e de negócio. No entanto, é de salientar que a dimensão económica foi a que mais melhorou de um momento para o outro.

Figura 4 - Estudo 1: desempenho organizacional percebido

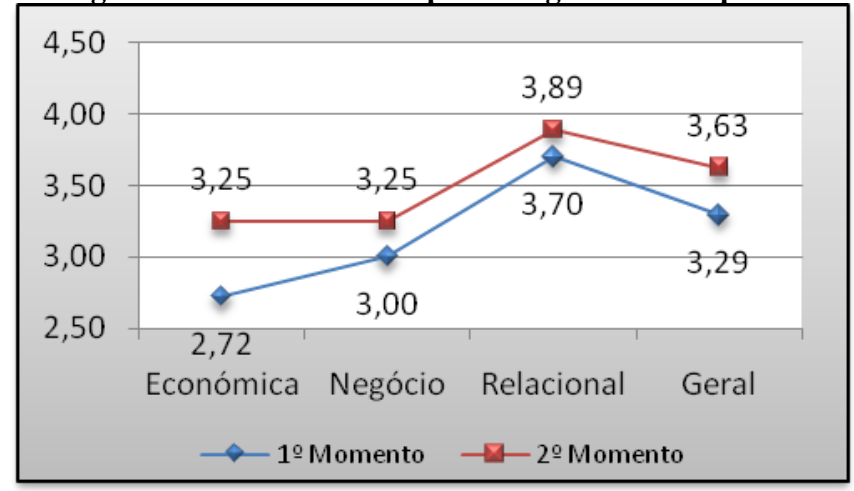




\section{Albino Lopes e Pedro Baioa}

\section{Gestores: Competências}

Ao observar as competências por orientação de gestão relativamente ao gestor $A_{1}$ (Figura 5), verifica-se que, no $1^{\circ}$ momento, o gestor não apresenta grandes variações em relação às diferentes orientações, apresentando valores entre o médio e o alto. No entanto, do $1^{\circ}$ para o $2^{\circ}$ momento, os valores desceram em todas as dimensões, com especial ênfase para as regras.

Figura 5 - Estudo 1: gestor $A_{1}$, orientações da gestão

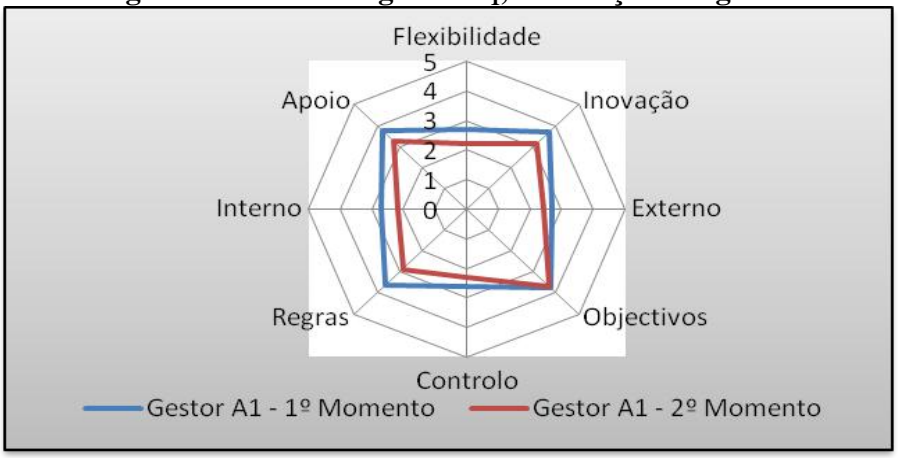

No que diz respeito ao gestor $\mathrm{B}_{1}$, pode-se observar (Figura 6) que o gestor apresenta valores altos em todas as dimensões (ênfase para os objetivos e inovação) e em ambos os momentos. Do $1^{\circ}$ para o $2^{\circ}$ momento houve um ligeiro aumento em quase todas as dimensões, sendo a dimensão das regras a exceção.

Figura 6 - Estudo 1: gestor $B_{1}$, orientações da gestão

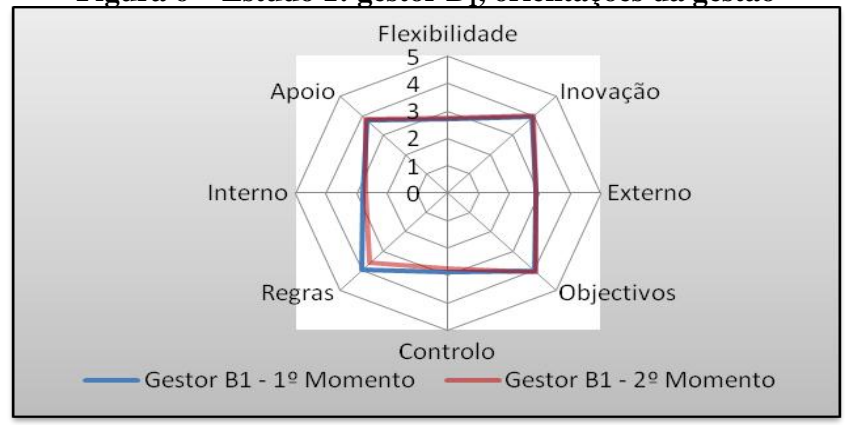

Por fim, o gestor $\mathrm{C}_{1}$ apresenta, num $1^{\circ}$ momento, a média mais baixa nas regras, ainda que não exista uma diferença muito significativa em 
relação às restantes, que apresentam valores altos (Figura 7). Por outro lado, denota-se que, para o $2^{\circ}$ momento, houve uma evolução negativa em todas as dimensões, com maior ênfase para a inovação.

Figura 7 - Estudo 1: gestor $\mathrm{C}_{1}$, orientações da gestão

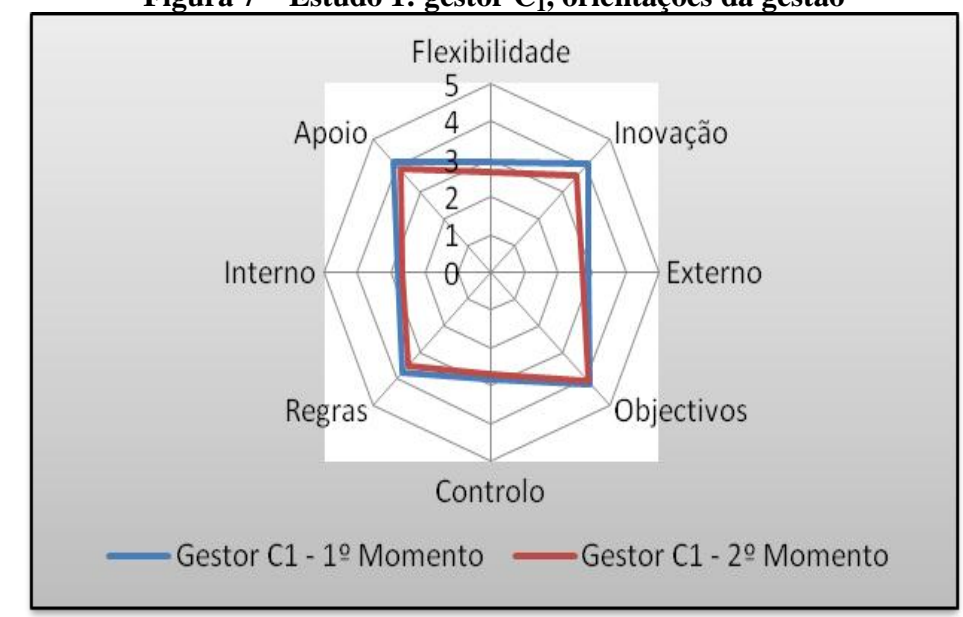

\section{Gestores: Confiança}

Ao analisar a confiança global no gestor $\mathrm{A}_{1}$ (Figura 8), pode verificarse que o gestor apresenta a maior média na dimensão da integridade $\left(1^{\circ}\right.$ momento) e benevolência ( $2^{\circ}$ momento; no polo oposto, e em ambos os momentos, surge a dimensão da confiança. De referir, também, que à exceção da dimensão da benevolência, todas as outras tiveram um decréscimo do $1^{\circ}$ para o $2^{\circ}$ momento.

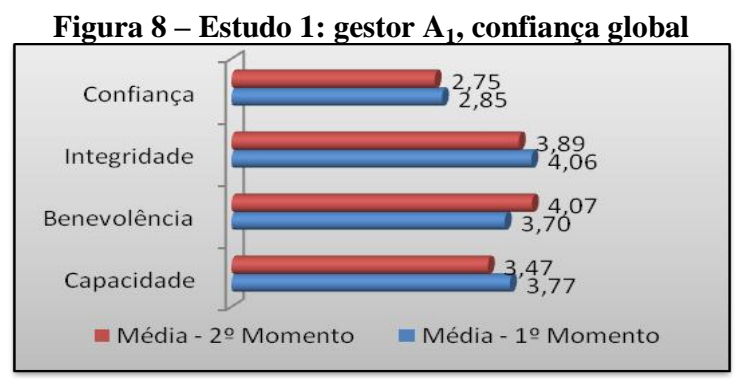

Relativamente ao gestor $\mathrm{B}_{1}$, e pela observação da Figura 9, denota-se que a dimensão com maior média em ambos os momentos é a da capacidade, contrariamente à dimensão da confiança, que apresenta valores relativamente medianos. É importante referir que a confiança 


\section{Albino Lopes e Pedro Baioa}

global no gestor teve uma evolução positiva, do $1^{\circ}$ para o $2^{\circ}$ momento, em todas as dimensões.

Figura 9 - Estudo 1: gestor $B_{1}$, confiança global

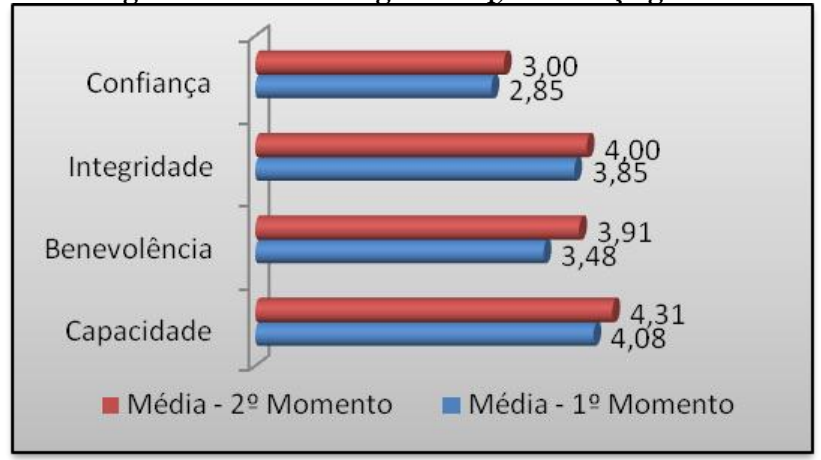

Por último, e tendo em consideração a confiança global no gestor $\mathrm{C}_{1}$, denota-se que a dimensão da confiança apresenta os valores mais baixos (em ambos os momentos), e que a integridade e capacidade $\left(1^{\circ}\right.$ momento) e benevolência ( $2^{\circ}$ momento) são as que apresentam os valores mais altos (Figura 10). Comparando os dois momentos, verificase que houve um aumento de confiança em quase todas as dimensões (ênfase para a benevolência), com exceção da integridade.

Figura 10 - Estudo 1: gestor $C_{1}$, confiança global

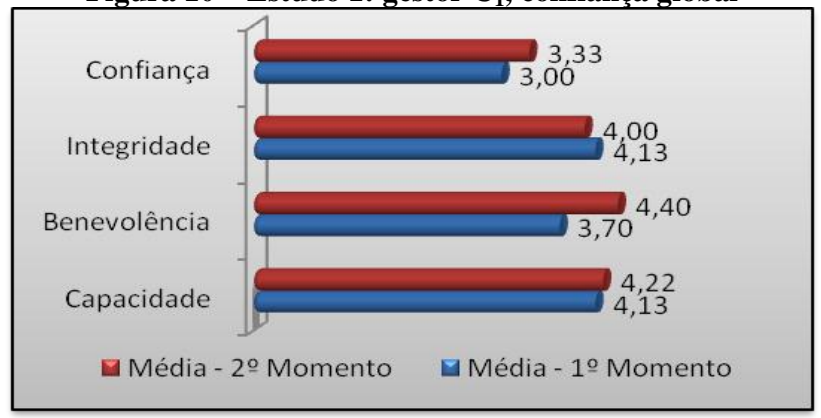

\section{DISCUSSÃO DOS RESULTADOS}

Far-se-á, neste ponto, a discussão de resultados. Não obstante, importa em primeiro lugar tecer algumas considerações em relação a uma intervenção realizada com o apoio de um consultor externo. 
Assim, logo após o $1^{\circ}$ momento do estudo, foi efetuada uma reestruturação da equipa de liderança na qual foram claramente definidos os papéis que cada gestor deveria desempenhar: o gestor A iria atuar preferencialmente na área da inovação, ou seja, iria assumir o papel de artista; o gestor B, por seu turno, iria atuar na área dos objetivos, i.e., iria desempenhar o papel de tecnocrata; o gestor $\mathrm{C}$ iria atuar na área do apoio, pelo que ia executar o papel de artesão; um quarto gestor (D) ficou responsável pela área das regras, pelo iria posicionar-se próximo do papel de tecnocrata; não obstante, este mesmo gestor iria também desempenhar o papel de político - dimensão sugerida por Lopes e Moreira (2004).

Prosseguindo agora para a discussão propriamente dita e tendo em atenção os resultados obtidos, verificou-se que as hipóteses $\mathbf{H}_{\mathbf{1 a}}$ e $\mathbf{H}_{\mathbf{1 b}}$ se verificam para algumas das relações estudadas, pois no estudo 1, os aumentos na perceção competências foram acompanhados por algumas diminuições nos hiatos culturais ( $\mathbf{H}_{1 \mathbf{a}}$; por ex., objetivos e regras) e aumentos no nível de confiança $\left(\mathbf{H}_{\mathbf{1 b}}\right.$; gestor $\mathrm{B}$, por exemplo); contrariamente as diminuições na perceção competências foram acompanhadas por aumentos nos hiatos culturais $\left(\mathbf{H}_{1 \mathbf{a}}\right.$; inovação e apoio, por ex.) e por diminuições no nível de confiança $\left(\mathbf{H}_{\mathbf{1 b}}\right)$ (gestor A, por exemplo).

As hipóteses $\mathbf{H}_{\mathbf{2}}$ e $\mathbf{H}_{2 \mathrm{~b}}$ verificam-se também para algumas relações, visto que a reestruturação da equipa de liderança terá contribuído para algumas diminuições nos hiatos culturais $\left(\mathbf{H}_{2 \mathbf{a}}\right.$; objetivos e regras) e aumentos no nível de confiança $\left(\mathbf{H}_{\mathbf{2 b}}\right.$; gestor B, por exemplo).

Com as hipóteses $\mathbf{H}_{\mathbf{3 a}}$ e $\mathbf{H}_{3 \mathrm{~b}}$ mantêm-se as conclusões anteriores, pois: a existência do papel de político terá contribuído para algumas diminuições nos hiatos culturais $\left(\mathbf{H}_{\mathbf{3}}\right.$; objetivos e regras) e aumentos no nível de confiança $\left(\mathbf{H}_{3 \mathbf{b}}\right.$; gestor $\mathrm{B}$, por ex.).

Finalmente, também para as hipóteses $\mathbf{H}_{4 \mathrm{a}}$ e $\mathbf{H}_{4 \mathrm{~b}}$ verificam-se algumas das relações estudadas, visto que o aumento das percepções do desempenho estará relacionado com as diminuições de alguns hiatos culturais $\left(\mathbf{H}_{\mathbf{4 a}}\right)$ e o aumento do nível de confiança $\left(\mathbf{H}_{\mathbf{4 b}}\right)$.

\section{CONCLUSÕES}

$\mathrm{Na}$ presente investigação foi estudada uma nova conceção da liderança - liderança partilhada - e o seu impacto no desempenho organizacional percebido, mediante a intermediação da cultura organizacional e dos níveis de confiança na gestão, tendo os resultados obtidos permitido validar as hipóteses formuladas.

Tornou-se evidente a importância do desempenho de papéis diferentes e complementares pelos elementos de uma equipa de liderança, visto que, 
uma situação em que tal não se verifique poderá afetar negativamente os resultados. Para a obtenção de resultados positivos, também se mostrou relevante a existência, na equipa de liderança, de um quarto papel de liderança - o político, neste caso concreto desempenhado por um gestor sénior, mas sem um papel explícito, e ao qual os outros reportam como a um responsável do pacto empresarial - e que procure obter a cooperação e a relevância de todos os elementos dessa equipa.

Outro fator que se revelou importante está relacionado com a necessidade dos gestores/líderes possuírem competências desenvolvidas e que se adequem ao papel ou papéis que estão a desempenhar, sem descurar as competências relacionadas com outros papéis.

Os resultados demonstraram também o impacto da cultura e da confiança na mediação da relação entre a liderança e o desempenho organizacional percebido. Assim, uma diminuição dos hiatos culturais e um aumento da confiança estarão associados a uma maior perceção do desempenho organizacional.

Globalmente, os resultados parecem corroborar o modelo de avaliação da liderança organizacional estudado, ou seja, a liderança como variável independente, a confiança e a cultura como variáveis mediadoras e o desempenho organizacional como variável dependente.

É importante referir, porém, algumas das limitações do presente estudo. Em primeiro lugar, a realização do estudo numa única empresa limita a possibilidade de generalização de resultados e comparação inter e intraindústrias. Salienta-se, em segundo lugar, o facto de apenas terem sido utilizadas técnicas descritivas de análise de dados. Como terceiro aspeto, refere-se a extensão do questionário, a qual poderá ter demovido alguns indivíduos de responderem. Por último, considera-se o facto de termos um $\mathrm{n}$ reduzido de respostas relativas às competências dos gestores e à confiança nos mesmos. 


\section{REFERÊNCIAS BIBLIOGRÁFICAS}

BARNEY, J. B. (1991), Firms Resources and Sustained Competitive Advantage, Journal of Management 17, 99-120.

BARNEY, J. B. (1995), Looking Inside for Competitive Advantage, Academy of Management Executive 9, 49-67.

BARNEY, J. B., M. Wright e D. J. Ketchen (2001), The resource-based view of the firm: Ten years after 1991, Journal of Management 27, 625-641.

BECKER, J. B. e B. Gerhart (1996), The Impact of Human Resource Management on Organizational Performance: Progress and Prospects, Academy of Management Journal 39, 779-801.

BLIGH, M. C., G. L. Pearce, e J. C. Kohles (2006), The Importance of Self- and Shared Leadership in Team Based Knowledge Work: A Meso-level Model of Leadership Dynamics, Journal of Managerial Psychology 21(4), 296-318.

BOTERF, G. L. (1998), Évaluer les compétences. Quels jugements? Quels critères? Quelles instances?, Education Permanent 135(2), 43151.

BOYATZIS, R. E. (1982), The competent manager. New York: Wiley.

BRADLEY, R. T. e K. H. Pribram (1996), Communication and Optimality in Biosocial Collectives, em D. S. Levine e W. S. Elsberry (Eds.), Optimality in Biological and Artificial Networks. Hillsdale, NJ: Lawrence Earlbaum Associates.

BROWNE, M. W. e R. Cudeck (1993), Alternative Ways of Assessing Model Fit, em K. A. Bollen e J. S. Long (Eds.), Testing Structural Equation Models. Beverly Hills, CA: Sage, 136-162.

CAMERON, K. S. e R. E. Quinn (2005), Diagnosing and changing organizational culture: based on the competing values framework (Revised Edition). San Francisco: Jossey-Bass.

CAMERON, K. S.; R. E. Quinn; J. DeGraff e A. V. Thakor (2006), Competing Values Leadership: Creating Value in Organizations. Massachusetts: Edward Elgar Publishing, Inc..

DAVIS, H. D., F. D. Schoormann, R. C. Mayer, e H. H. Tan (2000), The Trusted General Manager and Business Unit Performance: Empirical Evidence of a Competitive Advantage, Strategic Management Journal 21, 563-576.

DE SAÁ-PÉREZ, P. e J. M. García-Falcón (2002), A resource-based view of human resource management and organizational capabilities development, The International Journal of Human Resource Management 13(1), 123-140. 
DELANEy, J. T. e M. A. Huselid (1996), The impact of human resource management practices on perceptions of organizational performance, Academy of Management Journal 39(4), 949-969.

DESS, G. G. e R. B. Robinson Jr. (1984), Measuring Organizational Performance in the Absence of Objective Measures: The Case of the Privately-held Firm and Conglomerate Business Unit, Strategic Management Journal 5(3), 265-273.

FELÍCIO, M. J. (2007), Competências de Gestão e Desempenho Organizacional Percebido: Um Estudo na Indústria Portuguesa. Tese de Doutoramento em Gestão, ISCTE.

FELÍCIO, M. J., A. Lopes, F. Salgueiro e P. Parreira (2007), Competências de gestão: Um instrumento de medida para a realidade portuguesa, Revista Portuguesa e Brasileira de Gestão 6(3), 18-30.

GRANT, R. M (1991), The Resource-based Theory of Competitive Advantage: Implications for Strategy Formulation, California Management Review 17, 114-135.

GRANT, R. M. (2002), Contemporary Strategy Analysis: Concepts, Techniques, Applications ( $4^{\text {th }}$ Ed.). Blackwell Publishing.

HARDIN, R. (1991), Trusting Persons, Trusting Institutions, em R. J. Zeckahuser (ed.), Strategy and Choice. Cambridge, MA: MIT Press.

HARDY, C., N. Phillips, e T. Lawrence (1998), Distinguishing trust and power in inter-organizational relations: Forms and facades of trust, em Lane, C. e R. Bachmann (Ed), Trust within and between organizations: conceptual issues and empirical applications, Oxford: Oxford University Press, 64-87.

HART, S. L. e R. E. Quinn (1993), Roles executives play: CEOs, behavioral complexity, and firm performance, Human Relations 46(5), 543-575.

HAVE, T. S.; W. T. Have; A. F. Stevens; M. Vander Elst e F. Pol-Coyne (2003), Key Management Models: The Management Tools and Practices that Will Improve your Business. London: Prentice-Hall.

HOFSTEDE, G. (2001), Culture's Consequences: Comparing Values, Behaviors, Institutions, and Organizations across Nations $\left(2^{\text {nd }}\right.$ Ed). Thousand Oaks: Sage Publications.

KEATING, X. D., J. Guan, R. H. Fergunson, L. Chen e D. M. Bridges (2008), Psysical education teacher attitudes toward fitness tests scale: cross-revalidation and modification, Measurement in Physical Education and Exercise Science 12, 72-87.

KOLB, D. (1984), Experimental learning. Englewood Cliffs, NJ: Prentice-Hall. 
KOTTER, J. P. e J. L. Heskett (1992), Corporate Culture and Performance. New York: Free Press.

KRAMER, R. M. (2006), Organizational Trust: Progress and Promise in Theory and Research, em Kramer, R. M. (Ed), Organizational Trust: A Reader. New York: Oxford University Press, 1-17.

LANE, C (1998), Introduction: Theories and Issues in the Study of Trust, em C. Lane e R.Bachmann (Eds.), Trust Within and Between Organizations. New York: Oxford University Press, 113-145.

LAWLER III, E. E. (1999), Rewarding Excellence: Pay Strategies for the New Economy. San Francisco: Jossey-Bass Publishers.

LEBAS, M. e , K. Euske (2002), A Conceptual and Operational delineation of Performance, em Neely, A. (Ed), Business performance measurement: theory and practice, Cambridge: Cambridge University Press, 65-79.

LEWIS, J. e A. Weigert (1985), Trust as a Social Reality, Social Forces 43(4), 967-985.

LOPES, A. e P. Moreira (2004), A Liderança e a Cooperação InterPME's em Portugal: Estudo Longitudinal. Porto: Associação Empresarial de Portugal.

MABEY, C. e P. N. Gooderham (2005), The Impact of Management Development on Perceptions of Organizational Performance in European Firms, European Management Review 2, 131-142.

MAYER, R. C. e J. H. Davis (1999), The Effect of the Performance Appraisal System on Trust for Management: A Field QuasiExperiment, Journal of Applied Psychology 84(1), 123-136.

MAYER, R. C., J. H. Davis, e F. D. Schoormann (1995), An Integrative Model of Organizational Trust, Academy of Management Review 20(3), 709-734.

MCCLELLAND, D. C. (1973), Testing for competence rather than "intelligence", American Psychologist 1, 1-14.

MEYERS, L. S.; G. Gamst e A. J. Guarino (2006), Applied multivariate research: Design and interpretation. Thousand Oaks, CA: Sage.

MINTZBERG, H. (1989), Le Management: Voyage au Centre des Organizations ( $3^{\mathrm{a}}$ ed.). Paris: Les Éditions D’Organization.

MOREIRA, P. M. (2005), Constituição e Funcionamento de Redes InterOrganizacionais: Uma Perspectiva Diacrónica. Tese de Doutoramento em Gestão, ISCTE.

MORGAN, G. (1988), Riding the waves of change: Developing managerial competences for a turbulent world (2nd Ed). San Francisco: Jossey-Bass.

NEVES, J. e A. Lopes (2000), Cultura Organizacional, Satisfação, e Cidadania Organizacional, em ed.: Organizações em Transição - 
Contributos da Psicologia do Trabalho e das Organizações (Imprensa da Universidade, Coimbra).

NORDHAUG, O. (1993), Human capital in organisation. Oslo: Scandinavian University Press.

NUNNALLY, J. C. (1978), Psychometric Theory ( $2^{\text {nd }}$ ed.). New York: McGraw-Hill.

O'TOOLE, J, J. Galbraith, e E. E. Lawler III (2002), When Two (or More) Heads are Better than One: The Promise and Pitfalls of Shared Leadership, California Management Review 44(4), 65-83.

PEARCE, G. L. (2004), The Future of Leadership: Combining Vertical and Leadership to Transform Knowledge Work, Academy of Management Review 18(1), 47-57.

PEARCE, G. L. e J.A. Conger (2003), All those years ago: the historical underpinnings of shared leadership, em Pearce, C.L. e J.A. Conger (Eds.), Shared Leadership: Reframing the Hows and Whys of Leadership. Thousand Oaks, CA: Sage Publications, 1-18.

Pitcher, P. (1993), Balancing Personality Types at the Top, Business Quarterly 58(2), 47- 57.

PITCHER, P. (1997), The Drama of Leadership: Artists, Craftsmen, and Technocrats and the Power Struggle that Shapes Organizations and Societies. New York: John Wiley \& Sons, Inc.

QUINN, R. E., S. R. Faerman, M. P. Thompson, e M. R. McGrarth (1990), Maestria en la Gestión de Organizaciones: Un Modelo Operativo de Competencias. Madrid: Editiones Díaz de Santos, S.A.. QUINN, R. E. e J. Rohrbaugh (1983), A spatial model of effectiveness criteria: towards a competing values approach to organizational analysis, Management Science 29(3), 363-377.

ROBALO, A. (1995), Eficácia e eficiência organizacionais, Revista Portuguesa de Gestão 2/3, 105-116.

ROBERTS, N. C. (1996), Public Deliberation: An Alternative Approach to Crafting Policy and Setting Direction. Naval Postgraduate School, Monterey, CA.

ROWE, W. G. e J. L. Morrow Jr. (1999), A Note on the Dimensionality of the Firm Financial Performance Construct Using Accounting, Marker, and Subjective Measures, Revue Canadienne des Sciences de l'Administration 16(1), 58-70.

SANDBERG, J. (2000), Human competence at work: an interpretative approach, Academy of Management Review 43(1), 9-25.

SCHEIN, E. H. (1992), Organizational Culture and Leadership. San Francisco: Jossey-Bass Publishers.

SCHEIN, E. H. (1996), Three Cultures of Management: The Key to Organizational Learning, Sloan Management Review 38(1), 9-20. 
SCHWARTZ, Y. (1997), Les ingrédients de la compétence : un exercice nécessaire pour une question insoluble, Education Permanente 133, 9-34.

SENDELBACH, N. B (1993), The competing values framework for management training and development: A tools for understanding complex issues and tasks, Human Resource Management 32(1), 7599.

SIMON, C. A. (1998), Organizational Performance in the Public Sector: A Comparison of 77 Federal Bureaus Receiving or not Receiving the President's Quality Award 1992-1997. Ph.D. Thesis, United States International University.

SPENCER, L. M. e S. M. Spencer (1993), Competence at Work: Models for superiorperformance. New York: Wiley.

STIVERS, C. (1994), The Listening Bureaucrat: Responsiveness in Public Administration, Public Administration Review 54(4).

TEHRANI, M. e R.Noubary (2005), A Statistical Conversion Technique: Objective and Perceptive Financial Measures of the Performance Construct, Organizational Research Methods 8(2), 202-221.

VENKATRAMAN, N. e V. Ramanujam (1986), Measurement of business performance in strategy research: A comparison of approaches, Academy of Management Review 11, 801-814.

YAMMARINO, F. J. e L. E. Atwater (1993), Understanding selfperception accuracy: implications for human resource management, Human Resource Management 32(2/3), 231-247.

YUKL, G. A. (1989), Leadership in Organizations. Englewood Cliffs, NJ: Prentice Hall.

YUKL, G. A. (2009), Leadership in Organizations ( $7^{\text {th }}$ ed.). Englewood Cliffs, NJ: Prentice Hall. 
Anexo 1 - Questionário de competências de gestão

\begin{tabular}{|c|c|c|c|c|c|}
\hline Questões & 1 & 2 & & 4 & \\
\hline 1. Mantém a unidade motivada para os resultados & 1 & 2 & & 4 & \\
\hline 2. Cria coesão e espírito de grupo & 1 & 2 & & 4 & \\
\hline $\begin{array}{l}\text { 3. Projecta as actividades para chegar com eficiência aos } \\
\text { resultados }\end{array}$ & 1 & 2 & & 4 & \\
\hline 4. Facilita o diálogo e sabe c & 1 & 2 & 3 & 4 & \\
\hline $\begin{array}{l}\text { 5. Procura que os seus subordinados se desenvolvam } \\
\text { profissionalmente }\end{array}$ & 1 & 2 & & 4 & \\
\hline 6. Identifica tendências e planeia mudanças necessárias & 1 & 2 & 3 & 4 & \\
\hline 7. Mantém uma rede de contactos influentes & 1 & 2 & & 4 & \\
\hline 8. Resolve problemas de forma criativa e inteligente & 1 & 2 & & 4 & \\
\hline claros e define planos para os atingir & 1 & 2 & & 4 & \\
\hline $\begin{array}{l}\text { 10. Proporciona oportunidades de desenvolvimento dos seus } \\
\text { colaboradores }\end{array}$ & 1 & 2 & & 4 & \\
\hline $\begin{array}{l}\text { 11. Estimula a participação na tomada das decisões } \\
\text { evidenciando o sentido de equipa }\end{array}$ & 1 & 2 & & 4 & \\
\hline $\begin{array}{l}\text { 12. Trabalha eficazmente em situações de mudança e } \\
\text { ambiguidade }\end{array}$ & 1 & 2 & & 4 & \\
\hline anidade de trabalbo a atinair as metas fixadac & 1 & 2 & & 4 & \\
\hline $\begin{array}{l}\text { estabelecendo prazos realistas e estimando recursos } \\
\mathrm{S}\end{array}$ & e & 2 & & 4 & \\
\hline ue negociar bem envolvendo as partes & 1 & 2 & & 4 & \\
\hline 16. $s$ & 1 & 2 & & 4 & \\
\hline & 1 & 2 & & 4 & \\
\hline abertura e participação na equipa criando um ambiente & 1 & 2 & & 4 & \\
\hline $\begin{array}{l}\text { 19. Redige os documentos necessários com clareza e } \\
\text { objectividade }\end{array}$ & 1 & 2 & & 4 & \\
\hline 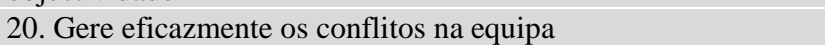 & 1 & 2 & & 4 & \\
\hline 21. $\mathrm{C}$ & 1 & 2 & & 4 & \\
\hline 22. $S$ & 1 & 2 & & 4 & \\
\hline 23. $\mathrm{I}$ & 1 & 2 & 3 & 4 & \\
\hline enhamento mantêm-se em situações & 1 & 2 & & 4 & \\
\hline & 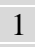 & 2 & & 4 & \\
\hline & 1 & 2 & & 4 & \\
\hline 27. D & 1 & 2 & & 4 & 5 \\
\hline & 2 & 2 & & 4 & \\
\hline 29. É & 1 & 2 & & 4 & \\
\hline (2) & 1 & 2 & & 4 & \\
\hline & 1 & 2 & & 4 & \\
\hline 32. $\mathrm{R}$ & 1 & 2 & & 4 & 5 \\
\hline 33. Dele & 1 & 2 & 3 & 4 & \\
\hline $\begin{array}{l}\text { 34. Chama os subordinados a participarem nas decisões da } \\
\text { equipa }\end{array}$ & 1 & 2 & & 4 & 5 \\
\hline
\end{tabular}


35. Consegue conjugar perspectivas conflituais

\begin{tabular}{l|l|l|l|}
2 & 3 & 4 & 5 \\
\hline
\end{tabular}

\begin{tabular}{|l|l|l|l|l|l|l|} 
36. Planeia e implementa mudanças oportunas para aperfeiçoar & 1 & 2 & 3 & 4 & 5
\end{tabular} o funcionamento da unidade de trabalho

37. Examina a informação com sentido crítico

$\begin{array}{lllllll}1 & 2 & 3 & 4 & 5\end{array}$

38. Procura sempre soluções em que todos ganham

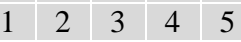

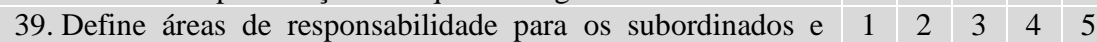
delega-as

\begin{tabular}{|l|l|l|l|l|l|} 
40. Demonstra grande motivação pelo seu papel & 1 & 2 & 3 & 4 & 5
\end{tabular}

\begin{tabular}{|l|l|l|l|l|l|} 
41. Confere o cumprimento das metas fixadas & 1 & 2 & 3 & 4 & 5 \\
\hline
\end{tabular}

\begin{tabular}{|l|l|l|l|l|l|}
\hline 42. Dá um sentido de ordem à actividade & 1 & 2 & 3 & 4 & 5 \\
\hline
\end{tabular}

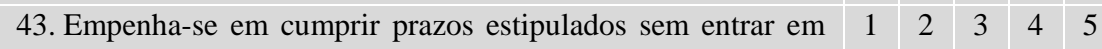
stresse

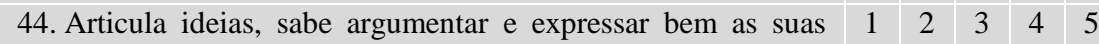
posições

\begin{tabular}{|l|l|l|l|l|l|}
\hline 45. Lida bem com as situações de mudança & 1 & 2 & 3 & 4 & 5
\end{tabular}

\begin{tabular}{|l|l|l|l|l|l|} 
46. Mostra empatia e preocupação com os subordinados & 1 & 2 & 3 & 4 & 5 \\
\hline
\end{tabular}

\begin{tabular}{|l|l|l|l|l|l|} 
47. Decide e não espera que as coisas aconteçam & 1 & 2 & 3 & 4 & 5 \\
\hline
\end{tabular}

\begin{tabular}{|l|l|l|l|l|l|l|} 
48. Entrega-se ao trabalho de alma e coração & 1 & 2 & 3 & 4 & 5
\end{tabular}

1) Nunca, 2) Raramente, 3) Por vezes, 4) Frequentemente, 5) Sempre

Fonte: Adaptado de Felício et al. (2007).

\section{Anexo 2 - Questionário de diagnóstico da cultura organizacional}

\begin{tabular}{|c|c|c|c|c|c|c|c|c|c|c|c|}
\hline Dimensão & Questões & & resa & orre & & & $\begin{array}{l}\mathrm{OC} \\
\text { occ } \\
\text { org }\end{array}$ & $\begin{array}{l}\text { le go } \\
\text { ress } \\
\text { niza }\end{array}$ & $\begin{array}{l}\text { stari } \\
\text { na } \\
\text { ão }\end{array}$ & & \\
\hline \multirow{4}{*}{ Inovação } & $\begin{array}{l}\text { 1. ASSUMIR } \\
\text { RISCOS (tomar } \\
\text { decisões que } \\
\text { impliquem } \\
\text { incerteza quanto } \\
\text { aos resultados) }\end{array}$ & (1) & (2) & (3) & (4) & (5) & (1) & (2) & (3) & (4) & (5) \\
\hline & $\begin{array}{l}\text { 5. ABERTURA À } \\
\text { CRÍTICA } \\
\text { (aceitação de } \\
\text { outras opiniões, } \\
\text { ainda que } \\
\text { diferentes) }\end{array}$ & (1) & (2) & (3) & (4) & (5) & (1) & (2) & (3) & (4) & (5) \\
\hline & $\begin{array}{l}9 . \\
\text { FLEXIBILIDADE } \\
\text { (adaptação às } \\
\text { circunstâncias) }\end{array}$ & (1) & (2) & (3) & (4) & (5) & 1) & (2) & (3) & (4) & (5) \\
\hline & $\begin{array}{l}15 . \\
\text { PIONEIRISMO } \\
\text { (procurar ser o } \\
\text { primeiro e o } \\
\text { melhor) }\end{array}$ & (1) & (2) & (3) & (4) & (5) & (1) & (2) & (3) & (4) & (5) \\
\hline Objectivos & $\begin{array}{l}\text { 3. OBJECTIVOS } \\
\text { CLAROS }\end{array}$ & (1) & (2) & (3) & (4) & (5) & & (2) & (3) & (4) & (5) \\
\hline
\end{tabular}




\begin{tabular}{|c|c|c|c|c|c|c|c|c|c|c|c|}
\hline & $\begin{array}{l}\text { (conhecer } \\
\text { concretamente as } \\
\text { metas a atingir) }\end{array}$ & & & & & & & & & & \\
\hline & $\begin{array}{l}\text { 4. ÊNFASE NA } \\
\text { REALIZAÇÃO } \\
\text { DA TAREFA } \\
\text { (preocupação com } \\
\text { o atingir } \\
\text { resultados) }\end{array}$ & (1) & (2) & (3) & (4) & $\stackrel{\text { (5) }}{\square}$ & (1) & (2) & (3) & (4) & (5) \\
\hline & $\begin{array}{l}\text { 6. PADRÕES } \\
\text { ELEVADOS DE } \\
\text { DESEMPENHO } \\
\text { (fazer muito e } \\
\text { bem) }\end{array}$ & (1) & (2) & (3) & (4) & (5) & (1) & (2) & (3) & (4) & (5) \\
\hline & $\begin{array}{l}\text { 13. EFICIÊNCIA } \\
\text { (fazer o mais } \\
\text { possível com os } \\
\text { menores recursos) }\end{array}$ & (1) & (2) & (3) & (4) & $\begin{array}{l}\text { (5) } \\
\square\end{array}$ & D & (2) & (3) & (4) & (5) \\
\hline \multirow{4}{*}{ Regras } & $\begin{array}{l}7 . \\
\text { CUMPRIMENTO } \\
\text { DAS REGRAS (as } \\
\text { pessoas são } \\
\text { estimuladas a } \\
\text { cumprir regras) }\end{array}$ & (1) & (2) & (3) & (4) & (5) & (1) & (2) & (3) & (4) & (5) \\
\hline & $\begin{array}{l}8 . \\
\text { PROCEDIMENT } \\
\text { OS } \\
\text { ESTABELECIDO } \\
\text { S (regras e } \\
\text { instruções formais } \\
\text { e escritas) }\end{array}$ & (1) & (2) & (3) & (4) & (5) & (1) & (2) & (3) & (4) & (5) \\
\hline & $\begin{array}{l}10 . \\
\text { FORMALIZAÇÃ } \\
\text { O (tudo passado a } \\
\text { escrito) }\end{array}$ & (1) & (2) & (3) & (4) & (5) & D & (2) & (3) & (4) & (5) \\
\hline & $\begin{array}{l}\text { 16. RESPEITO } \\
\text { PELA } \\
\text { AUTORIDADE } \\
\text { (respeitar e } \\
\text { valorizar as } \\
\text { chefias) }\end{array}$ & (1) & (2) & (3) & (4) & (5) & (1) & (2) & (3) & (4) & (5) \\
\hline \multirow[t]{2}{*}{ Apoio } & $\begin{array}{l}2 . \\
\text { COMPREENSÃO } \\
\text { MÚTUA } \\
\text { (entendimento } \\
\text { entre as pessoas) }\end{array}$ & (1) & (2) & (3) & (4) & (5) & 1) & (2) & (3) & (4) & (5) \\
\hline & $\begin{array}{l}\text { 11. APOIO AOS } \\
\text { COLEGAS } \\
\text { (preocupação com }\end{array}$ & (1) & (2) & (3) & (4) & (5) & & (2) & (3) & (4) & (5) \\
\hline
\end{tabular}




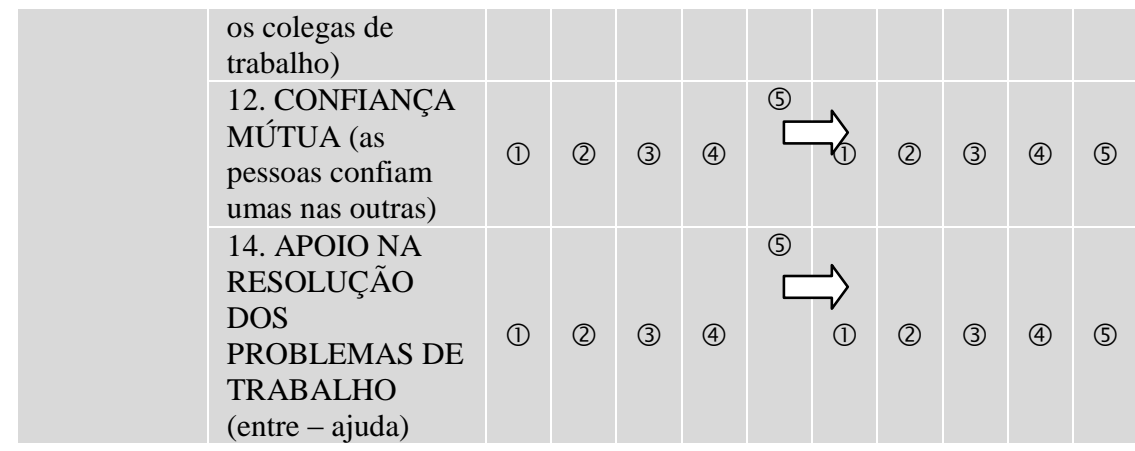

Nota: Este questionário segue uma escala Likert de 5 pontos, isto é, varia entre 1 (de modo nenhum) e 5 (muito)

Fonte: Felício (2007).

\section{Anexo 3 - Questões para avaliar a capacidade, benevolência, integridade e confiança}

\begin{tabular}{|c|c|}
\hline Dimensão & Questões \\
\hline \multirow{6}{*}{ Capacidade } & Esta gestão é bastante competente no desempenho da sua função \\
\hline & A gestão é conhecida por ser bem sucedida nas coisas que tenta fazer \\
\hline & $\begin{array}{l}\text { A gestão tem grande conhecimento acerca do trabalho que é } \\
\text { necessário fazer }\end{array}$ \\
\hline & $\begin{array}{l}\text { Sinto-me bastante confiante nas capacidades da gestão da nossa } \\
\text { empresa }\end{array}$ \\
\hline & $\begin{array}{l}\text { A gestão tem capacidades especializadas que podem fazer melhorar o } \\
\text { nosso desempenho }\end{array}$ \\
\hline & A gestão de topo é bem qualificada \\
\hline \multirow{5}{*}{ Benevolência } & A gestão interessa-se bastante com o meu bem-estar \\
\hline & $\begin{array}{l}\text { As minhas necessidades e aspirações são importantes para a gestão da } \\
\text { empresa }\end{array}$ \\
\hline & Conscientemente a gestão não faria nada que me afectasse \\
\hline & A gestão olha realmente para o que é importante para mim \\
\hline & A gestão sairia do seu mundo para me ajudar \\
\hline \multirow{6}{*}{ Integridade } & A gestão da nossa empresa tem um forte sentido de justiça \\
\hline & Nunca necessitei de saber se a gestão manterá a sua palavra \\
\hline & A gestão tenta fortemente ser justa nas negociações com outros \\
\hline & As acções e os comportamentos da gestão não são muito estáveis \\
\hline & Eu gosto dos valores que regem a gestão \\
\hline & Princípios íntegros parecem guiar o comportamento da gestão \\
\hline \multirow{4}{*}{ Confiança } & $\begin{array}{l}\text { Gostava realmente ter uma boa forma de ter um olho na gestão da } \\
\text { empresa }\end{array}$ \\
\hline & $\begin{array}{l}\text { Eu estaria disposto a deixar a gestão ter o controlo completo sobre } \\
\text { meu futuro nesta empresa }\end{array}$ \\
\hline & $\begin{array}{l}\text { Se fosse à minha maneira não deixaria a gestão ter nenhuma } \\
\text { influência sobre matérias que são importantes para mim }\end{array}$ \\
\hline & Estaria tranquilo confiando à gestão uma tarefa ou problema crítico \\
\hline
\end{tabular}




\section{Albino Lopes e Pedro Baioa}

para mim mesmo que eu não pudesse controlar as suas acções

Fonte: Adaptado de Mayer e Davis (1999).

\section{Anexo 4 - Questionário de desempenho organizacional}

\begin{tabular}{|c|c|}
\hline Dimensão & Questão \\
\hline \multirow{3}{*}{ Económica } & 1. O lucro (rendibilidade) da sua empresa \\
\hline & 2. A liquidez da sua empresa \\
\hline & 3. O crescimento das vendas na sua empresa \\
\hline \multirow{4}{*}{ Negócio } & 4. O desenvolvimento de novos produtos e/ou serviços \\
\hline & 5. A quota de mercado que a sua empresa tem \\
\hline & 6. A qualidade dos produtos e/ou serviços \\
\hline & 7. A satisfação geral dos clientes \\
\hline \multirow{3}{*}{ Relacional } & 8. A satisfação geral dos empregados \\
\hline & 9. As relações entre os empregados em geral \\
\hline & $\begin{array}{l}\text { 10. As relações entre a gestão de topo (administração) e os outros } \\
\text { empregados }\end{array}$ \\
\hline \multirow{2}{*}{ Geral } & 11. A produtividade da força de trabalho da empresa \\
\hline & 12. O desempenho global da empresa \\
\hline
\end{tabular}

Fonte: Baseado em Felício et al. (2007). 